\title{
E-governance using mobile applications: A case study of India during the COVID-19 pandemic
}

\section{Sandeep Goyal}

Thapar Institute of Engineering and Technology, India

sandy2u@gmail.com

\section{Anandan Pillai}

Publicis Media, India

\section{Sumedha Chauhan}

O. P. Jindal Global University, India

\section{Abstract}

Healthcare initiatives backed by electronic-governance (e-governance) principles have contributed well to the extant literature and practice. Governments and healthcare systems across the world were taken aback by the swamping impact of the COVID-19 pandemic. However, they reacted quickly by developing contact-tracing mobile applications (apps) for creating awareness, providing information about various healthcare initiatives, and helping citizens to use the required information in case of emergency. The major challenge was to develop such e-governance interventions in a short time and ensure their quick adoption among the masses. Hence, it is worthwhile to investigate the factors leading to the adoption of such e-governance initiatives, especially in the context of a widespread pandemic situation. The present study is an attempt to analyze the factors driving the intention to use contact tracing mobile apps launched by governments globally during the COVID-19 pandemic. We have conducted the study in the context of India, where the government launched a community-driven contact tracing mobile app for its citizens during the COVID-19 pandemic in April 2020. The study adopted an empirical approach to test how epistemic value, convenience value, conditional value, functional value, and privacy concerns influenced the intention to use this approach. The study found that intention to use such an app was positively influenced by functional value, which in turn was positively influenced by convenience and conditional values. It suggests that the convenience of using the app, perceived seriousness of the pandemic (i.e., conditional value), and utilitarian benefits (i.e., functional value) of the contact-tracing mobile app enhanced its acceptance. However, its novelty (i.e., epistemic value) and privacy concerns are not significant predictors of intention to use. The study recommends that the government should place more emphasis on improving the functional value which is driven by convenience and context-specific features to push the use of an e-governance initiative during the crisis.

Keywords: Intention to Use; COVID-19; Pandemic; Contact Tracing Mobile application; Theory of consumption values; Technology adoption; E-governance

\section{Introduction}

The outbreak of the COVID-19 pandemic resulted in a major risk to the health and well-being of individuals across the globe (Pan \& Zhang, 2020). The adverse impact of the COVID-19 pandemic was expected to be relatively more severe for densely populated developing nations like India, China, Brazil, etc. Developing countries are characterized by high population density, heterogeneity in terms of socio-economic level, and under-resourced health 
infrastructure in terms of hospital beds, doctors, nurses, diagnostics, and testing facilities for their population (Chib, van Velthoven, Michelle, \& Car, 2015). For example, India is one of the leading developing nations, comprising $17.7 \%$ of the global population, and was expected to face the worst impact during the COVID-19 pandemic (Worldometer, 2021; Ghosh, Nundy, \& Mallick, 2020). Therefore, it became critical for the Government of India (GoI) to take appropriate measures while dealing with under-resourced healthcare infrastructure issues, such as the shortage of hospital beds, testing kits and ventilators during the COVID-19 pandemic (Iqbal \& Dar, 2020).

To deal with the pandemic, several countries launched the community-driven contact tracing mobile application (app) to trace the COVID-19 infected people and their contact history. The use of the contact tracing mobile app for real-time tracking of the infected people and their interactions helped these countries in isolating and facilitating the fast recovery of the infected people as well as parallel profiling and recovery of contacts who interacted with these people during the onset of coronavirus symptoms. Examples of COVID-19 community-driven contact tracing mobile apps used by different countries include Immuni in Italy (Immuni Website, 2021), COVIDSafe in Australia, StopCovid in France, Corona App in Germany, MyTrace in Malaysia, CovidRadar in Mexico, ProteGO in Poland, Trace Together in Singapore, Swiss Contact Tracing App in Switzerland, Hayat Eve Sigar in Turkey, NHS COVID-19 App in the UK (O'Neill, Ryan-Mosley, \& Johnson, 2020).

The scarcity of resources and not-so-robust healthcare infrastructure, as well as the Internet and telecom setup in developing countries, especially those having high population density like India, makes them a robust case for launching e-governance-focused contact tracing mobile apps to enable better coordination, communication, prevention, and self-control during pandemic scenarios (Garg, Bhatnagar, \& Gangadharan, 2020). For example, during the COVID-19 pandemic, the GoI launched the community-driven contact tracing mobile app called Aarogya Setu on 2nd April 2020 as an e-governance initiative to enable prevention and control of this pandemic among the people of India (The Times of India, 2020). Within two weeks of its launch in India, the number of contact-tracing mobile app downloads reached 50 million (Banerjea, 2020).

During the early days post-launch, several citizens expressed scepticism about this mobile app, due to privacy and security issues highlighted by ethical hackers and some political opposition leaders in the country (The Economic Times, 2020). However, despite the criticism, the number of downloads has increased steadily for this contact tracing mobile app in India and reached more than 169 million in February 2021 (Aarogya Setu Website, 2021).

Similarly, contact tracing mobile apps have seen increasing adoption and usage numbers in various countries despite similar scepticism over security and privacy issues. Another example relates to the launch of a contact-tracing mobile app named "Immuni" by the Government of Italy on 1st June 2020, amidst privacy concerns (Reuters, 2020). Despite scepticism over privacy and security, the adoption of the contact tracing mobile app in Italy increased steadily after the launch. From June 2020 to February 2021, the app has been downloaded by more than 10.27 million users. Looking at growth trends, the number of downloads has increased from 10.245 million on 29th January 2021 to 10.272 million on 4th February 2021 (Immuni Website, 2021). However, in percentage terms, the adoption rate of contact tracing mobile apps in India and Italy is still only around $12 \%$ and $17 \%$, respectively, 
considering the approximate population of India at 1380 million and Italy at 60.46 million (Worldometer, 2021).

Though these contact tracing mobile apps have shown significant traction and facilitated realtime direct connections, thereby strengthening the impact of e-governance, there is still significant scope for increasing the penetration of these e-governance mobile apps among people in different countries. This implies that governments need to devise appropriate strategies, tactics and measures to enhance the adoption rate without enforcing compliance. At the same time, this also provides an opportunity for researchers to undertake future studies in this direction, in which they can focus on understanding the key enablers leading to the mass adoption of e-governance initiatives.

The gravity of the pandemic situation and governments' efforts to deal with such an unprecedented situation, presents an interesting and crucial question: what factors drive the citizens' intention to use the e-governance-initiated contact-tracing mobile app?

To answer the above question, we took the case of a contact tracing mobile app launched by the GoI during the COVID-19 pandemic. Further, we undertook the positivist approach to understand the influence of consumption factors, such as epistemic value, functional value, conditional value, convenience value, as well as privacy concerns on the intention to use. The extant literature has looked into the influence of consumption values and other related factors in driving the intention to use mHealth app services (Lee, Han, \& Jo, 2017); mobile health services (Lee \& Han, 2015); and mobile apps in general (Wang, Liao, \& Yang, 2013) among the public.

Similarly, there is existing literature which has evaluated the influence of privacy concerns and related factors in driving the behavioral intention to use mobile apps and related technology in healthcare services (Dhaggara, Goswami, \& Kumar, 2020; Gu, Xu, Xu, Zhang, \& Ling, 2017). Research articles like Lee et al. (2017) recommended the study of additional context and content values during future research in the context of intention to use mobile healthcare services across other countries. Lee et al. (2017) argued that context-content-related values can vary across countries, as cellular network availability, as well as healthcare systems, vary in terms of healthcare provider density.

Therefore, based upon a review of the extant literature, we realized that, if consumption values and privacy concerns are studied together, they can provide more meaningful and valuable insights into the intention to use a mobile app, especially in the context of health-related services. For this reason, we decided to use consumption and privacy values together in the research model to study the intention to use the mobile app.

An epistemic value construct measured how the mobile app helped to satisfy users' curiosity about COVID-19 cases around them in a novel manner. A conditional value construct helped to measure the perceived seriousness of the COVID-19 risk amongst app users. Convenience value measured the extent to which the app was convenient for users to remain updated about the situation around them. The functional value construct highlighted the utilitarian benefits one could achieve by using the app. Finally, the privacy concerns construct helped in understanding whether mobile app users were concerned about their privacy exposure due to its usage. The extant literature has ample proof of the relevance of these constructs to the adoption of a technology (Gu et al., 2017; Lee \& Han, 2015; Lee et al., 2017; Pihlström \& Brush, 2008; Sheth, Newman, \& Gross, 1991). 
Overall, the present study has the potential to make some unique contributions. First, it has examined how different factors influence the intention to use the mobile app launched by the government for electronic-governance (e-governance) and its functional value. As mentioned above, the influence of multiple constructs was investigated, each construct having a varying potential influence. Therefore, our research captures a comprehensive picture of mobile app adoption. Second, this study attempts to enrich insights by testing alternate models along with the main research model. This can help in gaining an in-depth understanding of the relationships among the constructs. Finally, though there have been several studies on the adoption of mobile apps, including health apps, their findings cannot be generalized to pandemic situations. Therefore, this study has the potential to add significant value to the existing literature and provide recommendations to policymakers on how to enhance the acceptance of a technology-oriented e-governance effort at the time of crisis.

The present study offers significant theoretical and practical implications. In the context of theoretical considerations, this is one of the first research studies that has integrated the theoretical constructs of privacy concerns and consumption values while investigating public intention to use the contact-tracing mobile app during the pandemic scenario. Another key theoretical implication involves the determination of factors contributing to the functional value, adoption, and usage of government-backed e-governance initiatives in a pandemic situation. Finally, this is one of the first e-governance-related research studies which has tested alternate models to explore other possible relationships between the constructs having a significant impact on the intention to use the contact-tracing mobile app. In the context of practical considerations, this is one of the first research studies, which has presented a unique perspective regarding the factors driving the adoption of a digital mobile app as an egovernance initiative in one of the most populated countries in the world, having huge socioeconomic diversity. Another key recommendation by this study involves focusing on functional value and context-specific features, rather than the novelty aspect, while launching e-governance initiatives among the general public in a heterogeneous country like India.

The research paper is structured as follows. Section 2 develops the theoretical background and hypotheses. The research methodology is explained in section 3. Section 4 analyses the data and presents the results. The results are discussed in detail in section 5. Finally, section 6 presents the concluding remarks, theoretical and practical implications, limitations and future research directions.

\section{Theoretical Background and Hypothesis Development}

Rapid advancements in information and communication technologies (ICT) have resulted in inexpensive and pervasive technologies. Such technologies have enabled the governments of various nations to design and implement innovative solutions for better e-governance and value offerings to the citizens of their countries (Chauhan \& Kaushik, 2016). E-governance seeks to utilize ICT to provide government services digitally to organizations, citizens, and various levels of government to achieve the purpose of promoting good governance (Singh \& Sahu, 2018; Saxena, 2005). E-governance provides government information and public services on time, empowers the citizens to retrieve information without bureaucracy, and improves managerial effectiveness (Stemberger \& Jaklic, 2007). Thus, e-governance plays a vital role in streamlining public administration, which enables the establishment of seamless, citizencentric, polycentric, and cooperative governance (Leitner, 2003). Hence, the adoption of e- 
governance initiatives has been studied by several scholars (Chauhan \& Kaushik, 2016; Khanra \& Joseph, 2019).

A review of extant research studies related to adoption, acceptance, or use of technology brings out two perspectives. First, a majority of the studies related to the adoption, acceptance, or use of technology designed their conceptual model based on prevalent Information System theories like the Technology Acceptance Model (TAM), the Theory of Reasoned Action (TRA), and the Unified Theory of Acceptance and Use of Technology (UTAUT) (Lim, 2018a, 2018b; Lim, Lim, \& Phang, 2019). Second, few studies highlighted the need to look beyond traditional Information System theories of technology adoption (Pihlström \& Brush, 2008; Shroff \& Keyes, 2017; Okazaki, 2008). On similar lines, this study investigates the intention to adopt the contact-tracing mobile app, based on consumption values along with privacy concerns, instead of the TAM and UTAUT. The study focuses on understanding the significance of consumption values and privacy concerns as predictors for the adoption of technology, which is expected to add value in the context of the e-governance setup, accessibility to e-healthcare, or access to higher education online.

With growing internet and smartphone penetration, the launch and use of the mobile app or $\mathrm{m}$-app is gaining importance as a business phenomenon for service providers and as a differentiated value offering (content, information, or service-oriented) for users (Alhassan, $\mathrm{Li}$, Reddy, \& Duppati, 2020; Gu et al., 2017; Lee, 2010; Lu, Yao, \& Yu, 2005; Sarkar, Chauhan, \& Khare, 2020; Singh, 2020).

Many existing research studies have focused on understanding people's consumption, use, or adoption behavior in the context of the specific product or service offering. There are two elements in these types of studies. One of the elements involves the determinants which influence the outcome of the study. Another element relates to the outcome itself. In this study, the first element relates to the role of personal values, especially consumption values and privacy concerns in influencing the adoption or use behavior of consumers towards a particular product or service offering online (Gu et al., 2017; Sheth et al., 1991).

The second element in this study corresponds to the intention to use. Understanding the individual's intention to use different technology-based offerings has been observed as one of the key research themes across many studies published during $1990-2020$. Scholars have extensively used these theories to study the factors that influence users' technology usage intentions, such as the intention to use smartphones, mobile apps, and different modes of elearning scenarios, such as web-based learning, internet-based learning, and massive open online courses (MOOCs) (Chow \& Shi, 2014; Lee, 2010).

The expression 'intention to use' is derived from behavioral intention studies and is defined as the strength of an individual's intention to perform specified behavior (Fishbein \& Ajzen, 1975), which subsequently predicts the actual adoption of technology and its usage by the user (Agrebi \& Jallais, 2015). TAM related research studies have shown that intention to use has a positive impact on adoption behavior ( $\mathrm{Lu}, \mathrm{Lin}, \&$ Chen, 2017). There have been similar research studies that have observed a direct correlation between behavioral intention to use and actual usage, resulting in behavioral intention to use as a significant predictor of the action (Davis, Bagozzi, \& Warshaw, 1989; Hill, Smith, \& Mann, 1987).

In reference to the above background information, this section further explains the theory of consumption value and privacy theory. These theories have been applied to this study as 
appropriate in the context of the contact-tracing mobile app as an e-governance, communication, and preventive healthcare application during the COVID-19 pandemic situation.

\subsection{The Theory of Consumption Values}

Researchers in the social sciences stream, especially those involved in marketing-related studies are interested in analyzing the determinants of personal values which influence the adoption or intention to use among consumers of different kinds of products and service offerings (Lee \& Han, 2015; Sheth et al., 1991). Rokeach (1968, P.16) defined personal value as a "centrally held, enduring belief which guides actions and judgments across specific situations and beyond immediate goals to more ultimate end-states of existence." Understanding personal values, especially consumption values, helps in gaining an understanding of the behavioral pattern of the consumers, such as why certain consumers behave in a certain way (Sheth et al., 1991; Vinson, Scott, \& Lamont, 1977). Researchers argue that value cannot be a one-dimensional construct. Rather, it is considered to be a multidimensional phenomenon because people perceive value differently depending upon personal beliefs, needs, types of offering, mode of delivery, and preferences (Kumar, Sachan, \& Kumar, 2020; Lee \& Han, 2015, Sheth et al., 1991).

The theory of consumption values postulates that a consumer's positive attitude and buying decision are formed on the basis of their assessments of several value components, such as epistemic, conditional, functional, emotional, and social values (Sheth et al., 1991). Consumers' intention to buy a service or a product is enhanced or motivated by these values (Yang \& Lin, 2017). This theory is built upon three key axiomatic propositions: a) a consumer's choice is the function of multiple consumption values; b) the consumption values make distinct contributions in any buying situation; and c) these values are independent. This theory is applicable to various types of product classifications, such as durable and nondurable products and services (Gonçalves, Lourenço, \& Silva, 2016) and its predictive validity has been established in over 200 applications (Sheth et al., 1991). Hence, a decision might be affected by any or every consumption value.

Values help in guiding actions, judgments, attitudes, and comparisons between particular items and settings (Long \& Schiffman, 2000). Hence, there exists substantial support for the role of values in developing attitudes, beliefs, and behaviors (Kilbourne \& Pickett, 2008). Kumar et al. (2020) studied the behavioral intention of users towards internet banking and argued that consumption values regarding internet banking services have a moderating effect on customer satisfaction and subsequently influence their behavioral intention towards such services. There have been research studies in a similar context, which applied different consumption value dimensions to understand the context behind specific consumer or user behavior, especially in the context of healthcare-related offerings (Cengiz \& Kirkbir, 2007; Zainuddin, Russell-Bennett, \& Previte, 2013). Cengiz and Kirkbir (2007) identified the significance of functional, social, and affective values in the determination of perceived value for healthcare services. Zainuddin et al. (2013) investigated the role of functional and emotional values in the value creation process for preventive healthcare services. However, there is a dearth of research that has analyzed the role of different dimensions of personal values in the determination of usage behavior towards mobile apps, especially in a pandemic situation. 


\subsection{Privacy Theory}

Information privacy especially refers to the control of personal information, e.g., name, employment history, ethnicity, etc. (Lah, 2008). Smith, Dinev, and Xu (2011) described it as someone's state of restricted access to information about himself/herself. Westin (2003) argued that privacy is the psychological condition in which people can take a decision on what, how, and when information about them can be shared with others. Altman (1976) theorized that privacy is a boundary control process that can open and close the boundary between the self and one's social surroundings to achieve "the selective control of access to the self"'. Therefore, the principle behind privacy is the control of information.

Regarding privacy concerns, it is becoming increasingly important and relevant in influencing the intention-to-use behavior of consumers, especially in the context of technology-based products or service offerings. As technology is becoming all-pervasive in the lives of human beings, there is growing concern or scepticism that the majority of online technology platforms, especially mobile apps, are privacy-invasive. Many online or mobile apps collect personal details which are not required for the functionality of the application and use those details for unauthorized purposes (Gu et al., 2017).

\subsection{Conceptual Model - Constructs}

\subsubsection{Epistemic Value}

According to Sheth et al. (1991, p. 162), epistemic value is defined as, "the perceived utility acquired from an alternative's capacity to arouse curiosity, provide novelty, and satisfy a desire for knowledge seeking." Any new experience or an alternative that is being chosen for avoiding boredom, or fulfilling curiosity, or experiencing new learning provides epistemic value (Sheth et al., 1991). For example, the adoption of online games or mobile apps can be triggered by the curiosity or desire to experience the new technology-based offering (Okazaki, 2008; Pihlström \& Brush, 2008). People try a new product or service because they get bored with the continued use of the existing brand and want to try something new in their life out of curiosity or variety-seeking behavior (Chen \& Kotz, 2000; Steenkamp \& Baumgartner, 1992). Thus, epistemic value can play an essential role in the intention to use something different.

However, Sheth et al. (1991) also highlighted that, due to epistemic value, customers who go for a new or alternative experience may return to their original consumption patterns after experiencing the change. Thus, epistemic value may or may not provide a long-lasting impact on the use of a new or alternative product unless and until the user finds high utility value while using it.

The contact-tracing mobile app was primarily launched to provide real-time utilitarian value to mobile users during the pandemic situation of COVID-19. This app holds functional value because it provides the users the opportunity to get real-time information regarding COVID19 statistics, infected cases around them, and steps to be taken in case of any related health issue. This app carries detailed audio-visual messages featuring prominent personalities from Bollywood (Hindi movie industry). These messages help the users understand the precautions they should take during the COVID-19 pandemic, besides giving health and hygiene tips, etc. Apart from the continuous awareness that GoI created about COVID-19 through traditional media channels like television, newspapers, and radio, the launch of the Aarogya Setu app as a novel technology-based real-time interface is considered a commendable initiative. Based on the above discussion, we propose the following hypothesis: 
H1: Epistemic value positively impacts the functional value of the e-governance-initiated contact tracing mobile app.

\subsubsection{Conditional Value}

Sheth et al. (1991) define conditional value as "The perceived utility acquired by an alternative as the result of the specific situation or set of circumstances facing the choice maker." A consumer's decision to use a particular product or service depends upon the context or situation around him or her. For example, people take a significant interest in buying wedding-related products and services during the time leading up to their wedding event. Similarly, the Christmas tree sale is maximum during the Christmas season, rather than the whole year. Conditional value represents the social or functional value which is experienced in a specific context or situation and is independent of time and location (Pihlström \& Brush, 2008; Sheth et al., 1991).

According to Pihlström and Brush (2008), the majority of users associate high conditional value with a specific product or service offering if it adds value to them in specific scenarios, like unplanned situations, unfamiliar locations, or during the state of movement from one place to another. This also implies that the extent of conditional value derived from the product or service depends, to a certain extent, on the mental state and location of the user.

The rationale explained here fits well into the context of the conditional value derived from information services or mobile apps during a pandemic situation like COVID-19. During COVID-19, several countries launched a contact-tracing mobile app to collect and share realtime information with app users regarding COVID-19 cases, symptoms, preventive measures, and self-control actions anytime and anywhere.

This indicates that the contact-tracing mobile app has high conditional value during pandemic situations, because it enables real-time access to time-critical information for the citizens anytime and anywhere. Once citizens start using the contact-tracing mobile app, they find it useful in getting timely access to required information, thereby safeguarding themselves from infection by the coronavirus. This creates a positive impact in terms of the functional appeal of this app. Based on this discussion, we hypothesize a positive relationship between conditional and functional value dimensions.

H2: Conditional value positively impacts the functional value of the e-governance-initiated contact-tracing mobile app.

\subsubsection{Convenience Value}

Convenience value relates to the ease and speed of effectively and conveniently achieving a particular task (Anderson \& Srinivasan, 2003). Convenience value for a product or service is determined based on the value addition that it provides to the consumer in terms of minimizing the time and effort required for completing a task (Colwell, Aung, Kanetkar, \& Holden, 2008; Pihlström \& Brush, 2008; Singh, 2020).

Pagani (2004) argues that the speed of use is one of the key determinants in the adoption of multimedia mobile by the users. In the healthcare context, Zhang, Yu, and Shen (2012) highlight how the electronic health records system can lead to an increase in convenience value due to quick and easy data input, storage, distribution, and retrieval. In the context of information services and mobile apps, convenience value is considered to be one of the key dimensions for enhancing utilitarian value because it promotes self-service, thereby 
improving the speed of access to information in optimal time and with minimal efforts (Pura, 2005; Rintamäki, Kanto, Kuusela, \& Spence, 2006; Singh, 2020).

Singh (2020) reviewed the post-adoption behavior of users towards mobile payment systems and argued that effort expectancy or user-friendliness of the mobile payment system promotes initial acceptance as well as continuance intention towards its use. In this study, the convenience value of the contact tracing mobile app in the context of COVID-19 lies in its ease of use and $24 \times 7$ self-service access to real-time information regarding the overall count of pandemic cases in the affected countries, as well as the count of infected patients in adjoining areas, and details regarding nearby hospitals and health centers for any emergency.

These apps provide an opportunity for self-service and real-time access to COVID-19 data to millions of smartphone users across the affected countries (Lohchab, 2019). For example, during the COVID-19 pandemic, the Government of India increased the penetration of the contact-tracing mobile app by setting up an Interactive Voice Response System (IVRS) for feature phone users in India (Agarwal \& Sharma, 2020). This IVRS setup was expected to help GoI reach 900 million citizens of India. This setup enabled self-service access in $24 \times 7$ mode to feature phone users, who started calling on the IVRS toll-free number to discuss their medical condition and get timely advice regarding the appropriate medical intervention. Based on the above discussion, we formulate the following hypothesis regarding the relationship between convenience and functional value dimensions in the context of using a contact-tracing mobile app during the pandemic situation.

H3: Convenience value positively impacts the functional value of the e-governance-initiated contact tracing mobile app.

\subsubsection{Functional Value}

Functional value relates to the utilitarian functions which are offered by a specific product or service. Tzeng (2011) argues that functional value involves the manifestation of the product's quality and feature attributes, resulting in utilitarian performance. Sheth et al. (1991) define functional value as the product's ability to perform a functional, utilitarian, or physical purpose. Singh (2020) argues that the utility value of the mobile payment system enhances the performance expectancy belief of the users, which in turn significantly influences their continuance intention.

This value dimension is considered to be a primary driver in the choice and usage behavior of the consumer. Another way of looking at functional value is that it involves the value derived from efficient task fulfillment in terms of monetary value and superiority, compared to available alternatives, availability, reliability, durability, and usability (Holbrook, 1994; Pihlström \& Brush, 2008).

In this study, the contact-tracing mobile app's functional value is driven by the bundle of value-added features offered by the app to its users during the pandemic situation. During the pandemic situation of COVID-19, the key offerings of the contact-tracing mobile app launched by the governments in different countries involve educating/alerting the user anytime and anywhere, about their contact with a COVID-19 patient and corrective measures in case of any symptoms. The app also offers access to telemedicine, real-time information regarding nearby e-pharmacy, and diagnostic services (Firstpost, 2020). Moreover, at least in the case of the Indian app, using the app does not get counted in the daily mobile data usage limit (Firstpost, 2020). Geographically stranded citizens of the country can apply for an e-pass through the 
contact-tracing mobile app to seek permission to travel across district and state borders. All these features of the contact-tracing mobile app have significantly enhanced its functional value, which in turn strengthens its usability among the people of India. We propose the following hypothesis regarding the relationship between functional value and intention to use the contact-tracing mobile app during the pandemic situation.

H4: Functional value positively impacts the intention to use the e-governance-initiated contact-tracing mobile app.

\subsubsection{Privacy Concerns}

There is increasing concern for privacy in this digital world. Gu et al. (2017) define privacy concerns in the context of an Android app as the extent to which users feel concerned about the possible loss of privacy when they determine whether to download an app. Many research studies look at the relationship between privacy-invasive mobile apps or web applications visà-vis users' intention to use those mobile apps or web applications ( $\mathrm{Gu}$ et al., 2017). The dominant view in these research studies implies that privacy concerns negatively affect the intention of the individual towards the use of digital technologies like mobile apps or web applications for online information, electronic-content, electronic-learning, or buy-sell transactions (Angst \& Agarwal, 2009; Dinev \& Hart, 2006).

There has been a gradual shift in research studies from general towards context-specific privacy concerns over a period. It has been observed that the extent of privacy concerns depends upon the context in which a particular digital technology is supposed to be used $(\mathrm{Xu}$, Teo, Tan, \& Agarwal, 2012). The authors argue that context-specific privacy concerns involve the linkage between an individual's assessment of privacy concerns and a specific context with a specific external agent. This implies context-specific privacy concerns vary across individuals and are driven by the individual's assessment of the situational context.

Many experts have raised privacy concerns regarding the contact-tracing mobile apps launched by different countries as an e-governance initiative during the COVID-19 pandemic for the following reasons. First, the contact-tracing mobile app launched in countries like India uses GPS tracking and Bluetooth data to track users' movement and share real-time information about the infected cases within a close radius (The Quint, 2020). Second, it has raised concerns among the experts due to below-par performance on data minimization in some countries (The Hindu, 2020; The Quint, 2020; Firstpost, 2020). This means the contacttracing mobile app in some countries is collecting more data than needed for it to work. Moreover, there is no clarity on how long the details of the infected and healthy users will be kept in the system. Third, the app has attracted criticism for lack of transparency in some countries like India, as the app was not open-sourced at the time of launch and so third parties could not review its code and methods (The Hindu, 2020; The Quint, 2020; Firstpost, 2020). Fourth, governments in countries like India have not defined a public sunset clause for the app (Firstpost, 2020). This implies there is no clarity as to when this app will cease to be employed. To add complexity and concerns in the minds of the potential users, some countries, like India, initially pushed the use of the contact-tracing app as a mandatory step for smartphone users in some states of India (The Hindu, 2020). The fact that many states in India have tried to make its use mandatory is likely to raise privacy concerns among users despite its functional value. 
While taking into consideration the view of the experts on contact-tracing mobile apps launched in different countries and rising concerns about their privacy attributes, we hypothesize that privacy concerns have a significant negative impact on the use of this app.

H5: Privacy concerns negatively impact the intention to use the e-governance-initiated contacttracing mobile app.

Table 1 provides a summary of the consumption value and privacy dimensions which act as key determinants towards intention to use the Aarogya Setu app, and the corresponding research model is highlighted in Figure 1.

\begin{tabular}{|c|c|c|}
\hline Dimension & Description & Sources \\
\hline $\begin{array}{l}\text { Epistemic } \\
\text { Value }\end{array}$ & $\begin{array}{l}\text { Perceived utility is acquired from an } \\
\text { alternative's capacity to arouse curiosity, } \\
\text { provide novelty, and satisfy a desire for } \\
\text { knowledge seeking. }\end{array}$ & $\begin{array}{l}\text { Chen and Kotz (2000); Okazaki (2008); } \\
\text { Pihlström and Brush (2008); Sheth et al. (1991); } \\
\text { Steenkamp and Baumgartner (1992) }\end{array}$ \\
\hline $\begin{array}{l}\text { Conditional } \\
\text { Value }\end{array}$ & $\begin{array}{l}\text { Perceived utility is acquired by an alternative } \\
\text { as the result of the specific situation or set of } \\
\text { circumstances facing the choice maker. }\end{array}$ & Pihlström and Brush (2008); Sheth et al. (1991) \\
\hline $\begin{array}{l}\text { Convenience } \\
\text { Value }\end{array}$ & $\begin{array}{l}\text { Ease and speed of achieving a particular task } \\
\text { effectively and conveniently }\end{array}$ & $\begin{array}{l}\text { Anckar and D'incau (2002); Anderson and } \\
\text { Srinivasan (2003); Colwell et al. (2008); } \\
\text { Pihlström and Brush (2008); Pagani (2004); Pura } \\
\text { (2005); Rintamäki et al. (2006); Zhang et al. } \\
\text { (2012) }\end{array}$ \\
\hline $\begin{array}{l}\text { Functional } \\
\text { Value }\end{array}$ & $\begin{array}{l}\text { The ability of the product to perform the } \\
\text { functional, utilitarian, or physical purpose }\end{array}$ & $\begin{array}{l}\text { Holbrook (1994); Sheth et al. (1991); Pihlström } \\
\text { and Brush (2008); Tzeng (2011) }\end{array}$ \\
\hline $\begin{array}{l}\text { Privacy } \\
\text { Concerns }\end{array}$ & $\begin{array}{l}\text { The extent to which users feel concerned } \\
\text { about the possible loss of privacy when they } \\
\text { are deciding whether to download an app }\end{array}$ & $\begin{array}{l}\text { Angst and Agarwal (2009); Dinev and Hart } \\
\text { (2006); Gu et al. (2017); Xu et al. (2012) }\end{array}$ \\
\hline
\end{tabular}

Table 1. Description of the Value and Privacy Dimensions

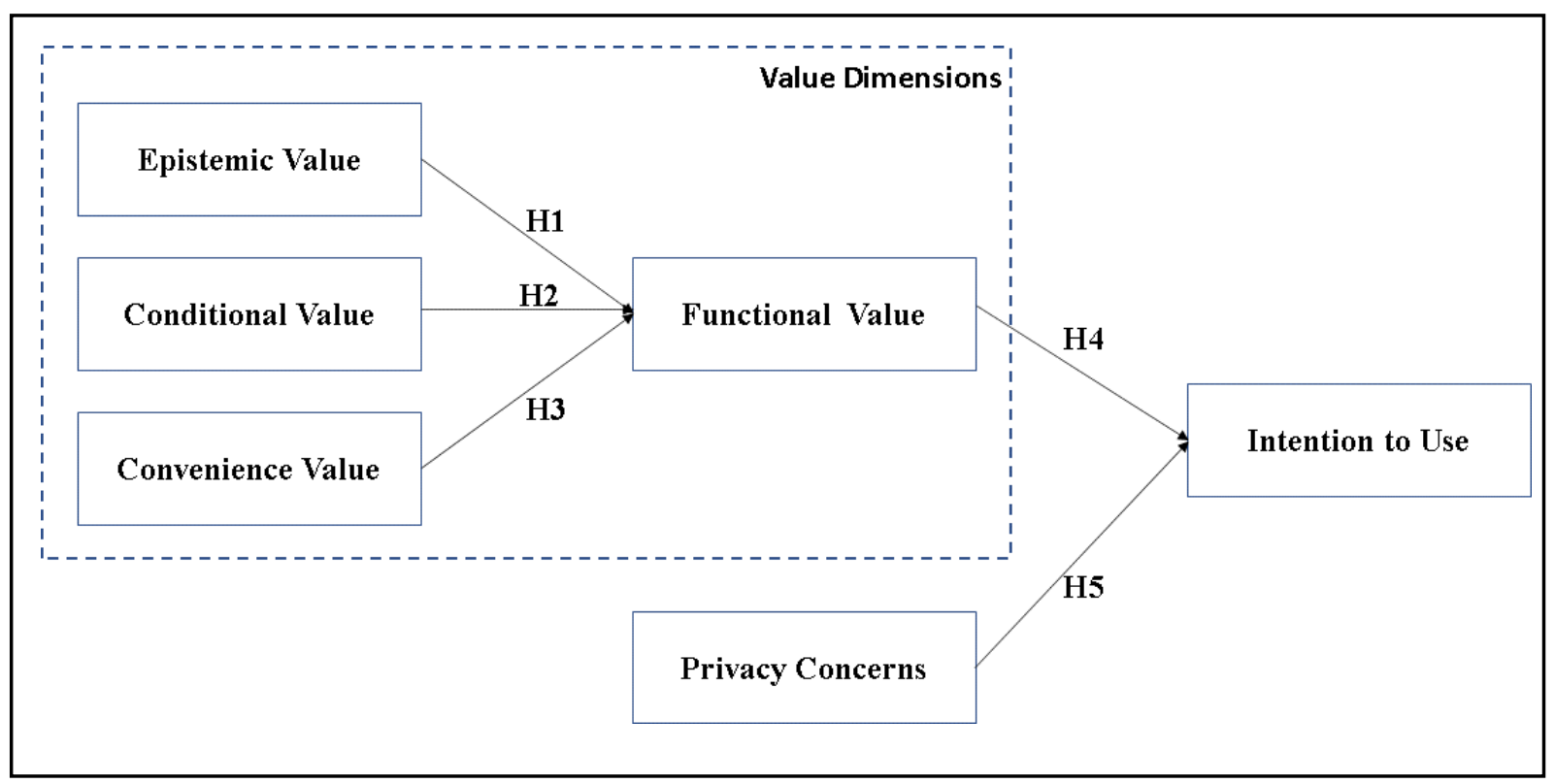

Figure 1. Research Model 


\section{Research Methodology}

\subsection{The Aarogya Setu Mobile App}

Aarogya Setu in the Sanskrit language meant, "bridge to health" (Clarance, 2020). Launched in April 2020, this community-driven contact-tracing mobile app became the world's fastest downloaded mobile tracing app, as it was downloaded over 50 million times in just 13 days from its launch (Banerjea, 2020). During April - June 2020, the Aarogya Setu app was downloaded over 100 million times (Clarance, 2020).

Aarogya Setu mobile app was designed, developed, and hosted by National Informatics Centre, under the guidance of the Ministry of Electronics and Information Technology. As of May 17, 2020, this app was made available in eleven vernacular languages of India, as well as in English. Amidst growing privacy and security concerns, GoI made the source code of this mobile app public on 26th May 2020. The total download figures for this contact-tracing mobile app have been growing steadily and surpassed 167.7 million and 169 million in December 2020 and February 2021, respectively, with daily active users in the range of around $4-5 \%$ (Aarogya Setu Website, 2021). A user would access the Aarogya Setu app an average of four times a day, with average daily time spent on the Aarogya Setu app around eight minutes. During 2020-21, the consistent upswing in the intention to use this community-driven contact tracing mobile app signifies the relevance and usefulness of this e-governance initiative among the public and the government for real-time information, monitoring, tracking, and self-control.

After downloading the contact-tracing app, the user gets a notification regarding the device's Bluetooth and location sharing data capture. The user registers himself/herself on the app by responding to a self-administered questionnaire. The questionnaire focuses on travel history, medical history, smoking habits, and whether he or she has had any COVID-19 symptoms. The app tracks the interaction between the user and other individuals with the help of Bluetooth and location. This creates a social graph that helps the citizens and the government / medical officers in identifying contact-tracing opportunities for further steps.

Though the Aarogya Setu app received global visibility due to its exceptional success, some leftists were busy maligning the product, rather than supporting the country's invention (O'Neill, 2020). Aarogya Setu's success was considered to have resulted due to the compulsory adoption strategy imposed by the Indian government on frontline COVID warriors, government officials, etc. (O'Neill, 2020). Journalists failed to report the importance of these COVID warriors who were fighting the battle without worrying about their health and it was essential to safeguard and support them. On the other hand, some myopic journalists missed the fact that there were several developed countries that adopted the compulsive adoption strategy for contact tracing apps (Farronato, Iansiti, Bartosiak, Denicolai, Ferretti, \& Fontana, 2020). In developed countries like Italy, even private sector employees were forced to download the contact-tracing app.

In a vast country like India, if the government had waited for the contact-tracing app to be downloaded voluntarily, contact tracing would have been much more difficult and there would have been many more infections. Hence, it was the right strategy adopted by the Indian government to first safeguard its frontline COVID warriors and thereby reach sufficient critical mass that would be required to ensure the contact tracing strategy was effective. 


\subsection{Measurements}

The measurements of the principal constructs such as privacy and intention of use were acquired from existing studies (Gu et al., 2017; Kijsanayotin, Pannarunothai, \& Speedie, 2009; Lu et al., 2005; Shroff \& Keyes, 2017) and tailored to fit the context of our research. These measurements were content validated based on the opinion of a panel of academicians in the management discipline.

The measurements of other principal constructs, namely functional value, conditional values, epistemic value, and convenience value were self-developed following the approach suggested by previous studies (Hoehle \& Venkatesh, 2015). First, the preliminary items were created by using the existing literature (Pihlström \& Brush, 2008; Sheth et al., 1991; Zandifar \& Badrfam, 2020) and discussion with a panel of academicians. We further invited two faculty members and four doctoral scholars who were acquainted with the present research subject to conduct a face validity check of the preliminary items. The items were further modified based on their opinion.

Second, we conducted a card-sorting test to assess the content validity of the items. We invited ten business school students to participate in this activity. The meaning of each construct was explained to these students. We constructed a matrix containing the definition of each construct in the top row and all the items in the first column. Every participant was provided with the matrix and asked to choose only one construct for each item. Later, the proportion of substantive agreement was calculated (Anderson \& Gerbing, 1991). The outcomes showed that the likelihood of every item being accurately classified was more than $60 \%$, meeting the conditions for content validity (MacKenzie, Podsakoff, \& Podsakoff, 2011).

Third, a pre-test was conducted to further validate the instrument. We measured the items using a seven-point Likert scale, ranging from strongly disagree to strongly agree. The participants of the pre-test were informed about the purpose of the present research. We collected 150 valid responses for the pre-test. The reliability of the measurement scale was analyzed by assessing the Cronbach's alpha values, which were found to be greater than 0.7 for each construct, signaling adequate reliability.

Our next step was to conduct exploratory factor analysis. We performed the KMO and Bartlett spherical tests to assess predictive validity. We found the KMO value as $0.775(>0.7)$, the approx. Chi-Square value as 1299.161, the degree of freedom as 171, and the significance level of $\mathrm{P}$ as $0.000(<0.05)$. These results suggested that the measurement instrument was appropriate for exploratory factor analysis (Churchill, 1979). As a result of exploratory factor analysis, the measurement items were categorized into four factors, together explaining $68.808 \%$ of the total variation. Ultimately, the measurement instrument of four constructs demonstrating good reliability and validity was ready for further use. Table 2 presents the list of constructs and their measurements.

\subsection{Data Collection}

We created an online survey form. The link to the survey form was emailed to university students, faculty members, and professionals working across different organizations in India. Through the email, the potential respondents were informed about the purpose of this academic research and assured of their anonymity. The data for the present study was collected from May 1, 2020 to May 30, 2020. 


\begin{tabular}{|c|c|c|c|}
\hline Construct & Items & Measurements & Source \\
\hline \multirow{5}{*}{$\begin{array}{l}\text { Functional } \\
\text { Value }\end{array}$} & FV1 & Aarogya Setu app helps in understanding how to self-isolate. & \multirow[t]{5}{*}{ Self-developed } \\
\hline & FV2 & $\begin{array}{l}\text { Aarogya Setu app helps in understanding what needs to be } \\
\text { done in case someone develops COVID-19 symptoms. }\end{array}$ & \\
\hline & FV3 & $\begin{array}{l}\text { Aarogya Setu app alerts immediately if someone in } \\
\text { proximity develops COVID-19 symptoms and tests positive. }\end{array}$ & \\
\hline & FV4 & $\begin{array}{l}\text { Aarogya Setu app helps in identifying the nearest } \\
\text { hospital/health center. }\end{array}$ & \\
\hline & FV5 & $\begin{array}{l}\text { Aarogya Setu app helps in remaining updated about COVID- } \\
19 \text { active cases in India. }\end{array}$ & \\
\hline \multirow{2}{*}{$\begin{array}{l}\text { Conditional } \\
\text { Value }\end{array}$} & CV1 & The unpredictability of the COVID-19 situation stresses me. & \multirow[t]{2}{*}{ Self-developed } \\
\hline & CV2 & The seriousness of the COVID-19 risk stresses me. & \\
\hline \multirow[t]{2}{*}{$\begin{array}{l}\text { Epistemic } \\
\text { Value }\end{array}$} & EV1 & $\begin{array}{l}\text { I am curious to stay informed regarding the COVID-19 cases } \\
\text { around me from the Aarogya Setu app. }\end{array}$ & \multirow[t]{2}{*}{ Self-developed } \\
\hline & EV2 & $\begin{array}{l}\text { Aarogya Setu app is a novel way to know about COVID-19 } \\
\text { situation around me. }\end{array}$ & \\
\hline \multirow[t]{2}{*}{$\begin{array}{l}\text { Convenience } \\
\text { Value }\end{array}$} & CONV1 & $\begin{array}{l}\text { Aarogya Setu app helps me to stay informed about COVID- } \\
19 \text { situation anytime and anywhere. }\end{array}$ & \multirow[t]{2}{*}{ Self-developed } \\
\hline & CONV2 & $\begin{array}{l}\text { Aarogya Setu app does not help me to stay informed about } \\
\text { COVID-19 situation more easily. (Reverse coded) }\end{array}$ & \\
\hline \multirow[t]{4}{*}{$\begin{array}{l}\text { Privacy } \\
\text { Concerns }\end{array}$} & PC1 & $\begin{array}{l}\text { I think the Aarogya Setu app over-collects my personal } \\
\text { information. }\end{array}$ & \multirow[t]{4}{*}{ Gu et al. (2017) } \\
\hline & PC2 & $\begin{array}{l}\text { I worry that the Aarogya Setu app may leak my personal } \\
\text { information to irrelevant third parties. }\end{array}$ & \\
\hline & PC3 & $\begin{array}{l}\text { I am concerned that the Aarogya Setu app may violate my } \\
\text { privacy. }\end{array}$ & \\
\hline & PC4 & $\begin{array}{l}\text { I am concerned that the Aarogya Setu app may misuse my } \\
\text { personal information. }\end{array}$ & \\
\hline \multirow{4}{*}{$\begin{array}{l}\text { Intention to } \\
\text { Use }\end{array}$} & IU1 & Using the Aarogya Setu app is worthwhile. & \multirow{4}{*}{$\begin{array}{l}\text { Kijsanayotin et } \\
\text { al. (2009); Lu et } \\
\text { al. (2005); Shroff } \\
\text { and Keyes (2017) }\end{array}$} \\
\hline & IU2 & I intend to use the Aarogya Setu app in the future. & \\
\hline & IU3 & I intend to use the Aarogya Setu app frequently. & \\
\hline & IU4 & I expect to continue using the Aarogya Setu app in the future. & \\
\hline
\end{tabular}

\section{Table 2. Constructs and Measurements}

The survey questionnaire had two questions at the beginning to screen out respondents who either did not download the Aarogya Setu app or who downloaded it but did not complete the self-assessment test on the app. In both scenarios, respondents were asked to submit the questionnaire without completing other questions in the survey. The link to the online survey questionnaire was sent to 1,350 Indian citizens of different age-groups. About 850 respondents clicked on the link and submitted the survey. Among the 850 responses received, 359 respondents had not downloaded the Aarogya Setu app, and 206 respondents had downloaded the app but did not attempt the self-assessment test. That left us with a final list of 285 respondents who had experienced the Aarogya Setu app themselves. This process was followed to ensure that the people in our survey were actual users of the Aarogya Setu app. 
As the country was under full lockdown during the data collection phase, the researchers did not have the opportunity to administer the survey questionnaire to respondents face-to-face. Instead, the researchers took the option of electronic distribution of survey questionnaires. The respondents were informed about the goal of the research so that they could fill up the survey questionnaire appropriately. The questions in the survey used a seven-point Likert scale ranging from strongly disagree to strongly agree. The demographics of these respondents are presented in Table 3. The sample represents the fact that India has one of the world's largest young populations (Statistics Times, 2020), while more than $50 \%$ of India's population was over 25 years old (Livemint, 2020). The sample selected for the study is adequately representative of the overall country's population trends with respect to age groups.

This sampling does have a bias towards respondents who were well-educated. However, given the external constraints, researchers could not get access to a larger set of respondents with varied educational backgrounds.

\begin{tabular}{|l|l|l|l|}
\hline Characteristics & $\%$ & Characteristics & $\%$ \\
\hline Gender & & Education & \\
\hline Male & $63 \%$ & Graduate & $59 \%$ \\
\hline Female & $37 \%$ & Post-Graduate & $32 \%$ \\
\hline & & Doctorate & $6 \%$ \\
\hline & & Other & $4 \%$ \\
\hline Age & & Region & \\
\hline $20-29$ & $14 \%$ & North India & $51 \%$ \\
\hline $30-39$ & $41 \%$ & South India & $16 \%$ \\
\hline $40-49$ & $27 \%$ & East India & $5 \%$ \\
\hline $50-59$ & $10 \%$ & West India & $12 \%$ \\
\hline$>60$ & $7 \%$ & Central India & $16 \%$ \\
\hline
\end{tabular}

Table 3. Demographics of Respondents

\section{Data Analysis and Results}

We applied the structural equation modeling (SEM) approach to examine the relationships present in the proposed research model. The survey data was assessed using variance-based partial least squares (PLS) SEM. We undertook the PLS SEM approach as it can handle complex predictive models. PLS structural modelling is a robust method to examine the causal model encompassing many constructs (Chin \& Newsted, 1999). We used the SmartPLS 3 software to examine the measurement model and the structural model in our research. To assess the measurement model, we evaluated the reliability and the validity of the measurements in the questionnaire. On the other hand, relationships present in the research model were examined using the structural model.

\subsection{Common Method Bias (CMB)}

We used procedural as well as statistical treatments for assessing the CMB issue (Podsakoff, MacKenzie, Lee, \& Podsakoff, 2003). Under the procedural treatment, respondents were informed that no response was right or wrong so they should remain candid while completing the survey. Additionally, they were notified that their identity would remain anonymous. 
Under the statistical treatment, Harman's single factor test was applied to assess the presence of $\mathrm{CMB}$, and the result indicated that only $23.462 \%$ of the variance was explained. Thus, we concluded that the CMB issue did not exist (Hew \& Kadir, 2017).

\subsection{Measurement Model}

To evaluate the measurement model, we tested reliability, convergent validity and discriminant validity. The reliability of the constructs was assessed via Cronbach's alpha and composite reliability values. As shown in Table 4, the value of every Cronbach's alpha and composite reliability score was greater than 0.7 , indicating a satisfactory level of reliability of scales (Fornell \& Larcker, 1981). Table 4 also shows the values of average variance extracted (AVE) to be greater than 0.5 , indicating convergent validity. Convergent validity was also evaluated through the standard loadings of the measurement items.

\begin{tabular}{|l|l|l|l|}
\hline \multirow{2}{*}{} & \multicolumn{2}{|l|}{ Reliability } & Convergent Validity \\
\cline { 2 - 4 } & Cronbach's Alpha & Composite Reliability & Average Variance Extracted (AVE) \\
\hline CV & 0.768 & 0.896 & 0.812 \\
\hline CONV & 0.739 & 0.884 & 0.792 \\
\hline EV & 0.828 & 0.919 & 0.850 \\
\hline FV & 0.869 & 0.905 & 0.657 \\
\hline IU & 0.859 & 0.904 & 0.702 \\
\hline PC & 0.847 & 0.888 & 0.667 \\
\hline
\end{tabular}

Table 4. Reliability and convergent validity of constructs

\begin{tabular}{|l|l|l|l|l|}
\hline Construct & Item & Loading & Standard Deviation & T Statistics \\
\hline Conditional Value & CV1 & 0.895 & 0.015 & 59.047 \\
\hline & CV2 & 0.907 & 0.014 & 65.144 \\
\hline Convenience Value & CONV1 & 0.905 & 0.021 & 43.461 \\
\hline & CONV2 & 0.875 & 0.026 & 33.086 \\
\hline Epistemic Value & EV1 & 0.895 & 0.216 & 4.139 \\
\hline & EV2 & 0.947 & 0.208 & 4.564 \\
\hline Functional Value & FV1 & 0.814 & 0.021 & 38.337 \\
\hline & FV2 & 0.853 & 0.015 & 56.006 \\
\hline & FV3 & 0.779 & 0.025 & 31.515 \\
\hline & FV4 & 0.781 & 0.023 & 34.238 \\
\hline & FV5 & 0.823 & 0.019 & 43.892 \\
\hline Intention to Use & IU1 & 0.835 & 0.021 & 38.985 \\
\hline & IU2 & 0.882 & 0.013 & 67.783 \\
\hline & IU3 & 0.786 & 0.026 & 30.753 \\
\hline & IU4 & 0.846 & 0.018 & 47.064 \\
\hline Privacy Concerns & PC1 & 0.905 & 0.192 & 4.708 \\
\hline & PC2 & 0.724 & 0.242 & 2.993 \\
\hline & PC3 & 0.849 & 0.201 & 4.231 \\
\hline & PC4 & 0.777 & 0.205 & 3.788 \\
\hline
\end{tabular}

Table 5. Item loadings

Table 5 shows that every loading was greater than 0.6, demonstrating an adequate level of convergent validity for all the constructs (Hair, Black, Babin, Anderson, \& Tatham, 2010). Furthermore, discriminant validity was assessed by comparing the square roots of AVEs with the values of inter-construct correlation. Table 6 indicates that the values of the square root of 
AVEs (diagonal values) were greater than the values of inter-construct correlation, signifying discriminant validity (Fornell \& Larcker, 1981).

\begin{tabular}{|l|l|l|l|l|l|l|}
\hline & CV & CONV & EV & FV & IU & PC \\
\hline CV & 0.901 & & & & & \\
\hline CONV & -0.046 & 0.89 & & & & \\
\hline EV & 0.023 & 0.022 & 0.922 & & & \\
\hline FV & 0.455 & 0.340 & 0.060 & 0.811 & & \\
\hline IU & 0.289 & 0.099 & -0.065 & 0.465 & 0.838 & \\
\hline PC & 0.035 & -0.024 & 0.044 & -0.017 & -0.089 & 0.817 \\
\hline
\end{tabular}

Table 6. Discriminant validity of constructs

\subsection{Structural Model}

The structural model was employed to evaluate the hypotheses developed in the present research. We computed the path coefficients and the R2 values to examine the structural model (Chin \& Newsted, 1999). Path coefficients act as the measurement for the statistical significance of the hypotheses, whereas R2 depicts the research model's capability to explain the variation in the dependent variables. The results of the structural model are presented in Table 7.

We found support for hypotheses $\mathrm{H} 2, \mathrm{H} 3$, and H4, while no support was found for $\mathrm{H} 1$ and H5. It was also revealed that the model explains $22.3 \%$ of the variation in intention to use and $34 \%$ of the variation in functional value.

\begin{tabular}{|l|l|l|l|l|}
\hline Hypothesis & Relationship & Path Co-efficient & T Statistics & Significance \\
\hline $\mathrm{H} 1$ & $\mathrm{EV} \rightarrow \mathrm{FV}$ & $0.042^{\text {ns }}$ & 0.805 & Not significant \\
\hline $\mathrm{H} 2$ & $\mathrm{CV} \rightarrow \mathrm{FV}$ & $0.471^{*}$ & 11.712 & Significant \\
\hline $\mathrm{H} 3$ & $\mathrm{CONV} \rightarrow \mathrm{FV}$ & $0.361^{*}$ & 8.545 & Significant \\
\hline $\mathrm{H} 4$ & $\mathrm{FV} \rightarrow \mathrm{IU}$ & $0.464^{*}$ & 11.724 & Significant \\
\hline H5 & $\mathrm{PC} \rightarrow \mathrm{IU}$ & $-0.08^{\text {ns }}$ & 1.228 & Not significant \\
\hline
\end{tabular}

Table 7. Structural model results

\section{Discussion}

This research paper is based on the theory of consumption values and used its multiple dimensions, including functional, social, epistemic, and conditional values. The element of privacy concerns in technology adoption was also included. The primary model was based on various studies in the literature (Gu et al., 2017; Kijsanayotin et al., 2009; Lu et al., 2005; Pihlström \& Brush, 2008; Sheth et al., 1991; Shroff \& Keyes, 2017; Zandifar \& Badrfam, 2020).

The scale items were adapted for the research context of the e-governance-related launch of a contact-tracing mobile app in India known as Aarogya Setu. Also, the researchers attempted alternate models as this is considered in the literature an effective way to understand a new context (Boon-Itt \& Wong, 2016; Falbo, Kim, \& Chen, 2009). Table 8 indicates a summary of the main model and four alternate models.

Figure 2 then depicts the four alternate models and the significance of the relationship between different constructs in each of these models. As the pandemic research context is severe and new to the Indian audience, we decided to test the alternate models and find if any alternative 
relationships could be explored. Convenience value and conditional value constructs showed consistent significant relationships with functional value and intention to use across the models in which they were tested. Also, the functional value had a significant relationship with the intention to use. It was clearly established that the stress and urgency of the situation (measured by Conditional Value) along with the convenience with which the technology could be adopted, led to strong functional value, which further led to intention to use.

\begin{tabular}{|l|l|l|l|l|l|}
\hline Relationships & $\begin{array}{l}\text { Main } \\
\text { Model }\end{array}$ & $\begin{array}{l}\text { Alternate } \\
\text { Model 1 }\end{array}$ & $\begin{array}{l}\text { Alternate } \\
\text { Model 2 }\end{array}$ & $\begin{array}{l}\text { Alternate } \\
\text { Model 3 }\end{array}$ & $\begin{array}{l}\text { Alternate } \\
\text { Model 4 }\end{array}$ \\
\hline $\mathrm{EV} \rightarrow \mathrm{FV}$ & & & & & \\
\hline $\mathrm{CV} \rightarrow \mathrm{FV}$ & 0.471 & 0.472 & & 0.474 & 0.472 \\
\hline $\mathrm{CONV} \rightarrow \mathrm{FV}$ & 0.361 & 0.364 & & 0.364 & 0.362 \\
\hline $\mathrm{PC} \rightarrow \mathrm{FV}$ & & & & & \\
\hline $\mathrm{EV} \rightarrow \mathrm{IU}$ & & & & & \\
\hline $\mathrm{CV} \rightarrow \mathrm{IU}$ & & & 0.326 & 0.305 & \\
\hline $\mathrm{CONV} \rightarrow \mathrm{IU}$ & & & 0.121 & 0.119 & \\
\hline $\mathrm{PC} \rightarrow \mathrm{IU}$ & & & & & \\
\hline $\mathrm{FV} \rightarrow \mathrm{IU}$ & 0.464 & & & & 0.469 \\
\hline
\end{tabular}

Table 8. Relationships Summary across various alternate models tested

Note: Highlighted cells indicate significant relationships. Numbers within cells indicate the path coefficients

As shown by the results of the four alternate models tested, conditional and convenience values were found to have a significant positive impact on functional value and the intention to use. Thus, users of the contact-tracing mobile app had easy access to utilitarian benefits during stressful times.

The apparent reasons behind these findings are as follows. First, contact-tracing mobile apps were launched by the governments of different countries, including India, as an e-governance initiative during the COVID-19 pandemic situation. Considering the COVID-19 context, the intention to use this mobile app was not driven by the epistemic value or novelty aspect. The contact-tracing mobile app is looked upon primarily from the functional value perspective when it comes to intention to use.

Second, again considering the pandemic context, intention to use among citizens of countries like India is driven by the functional value-addition rather than privacy features. As highlighted in the literature, there is no denying the fact that users value privacy more than many other aspects while using any mobile app (Angst \& Agarwal, 2009; Dinev \& Hart, 2006; $\mathrm{Gu}$ et al., 2017; Xu et al., 2012). However, the COVID-19 pandemic subdued the privacy concerns, as making use of online contact-tracing mobile apps has become a necessity for the people in this pandemic situation, rather than an optional choice to remain connected with the relevant information.

The insignificant relationship between privacy concerns and intention to use was commonly found across all the alternate models. However, this comes as a huge surprise and is in contrast to the extant literature where privacy concerns were established to be a key determinant in technology adoption (Angst \& Agarwal, 2009; Dinev \& Hart, 2006; Gu et al., 2017; Xu et al., 2012). With the background of multiple instances when the push for the adoption of contact tracing mobile app in countries like India was criticized publicly by opposition political parties and some ethical hackers for bugs with respect to privacy, its insignificance as a contributor to 
the intention to use was surprising. The reason for such a relationship could be that, in the case of a pandemic scenario, users probably do not worry much about their privacy, but attach more importance to the utilitarian benefits of the technology that would come to their rescue in this stressful scenario. This result opens up a plethora of discussions and needs stronger evaluation in the future.

Another surprise element from the main and alternate models is the insignificant relationship of epistemic value with functional value and intention to use. It simply means that novelty and curiosity of the contact-tracing mobile app neither enhance the functional value of the app nor result in people's intention to use it. The apparent reason behind this finding is that the novelty feature does not seem to influence technology adoption among the users during an emergency. During the COVID-19 pandemic situation, users in countries like India have preferred contact-tracing mobile apps primarily due to the conditional and convenience attributes.

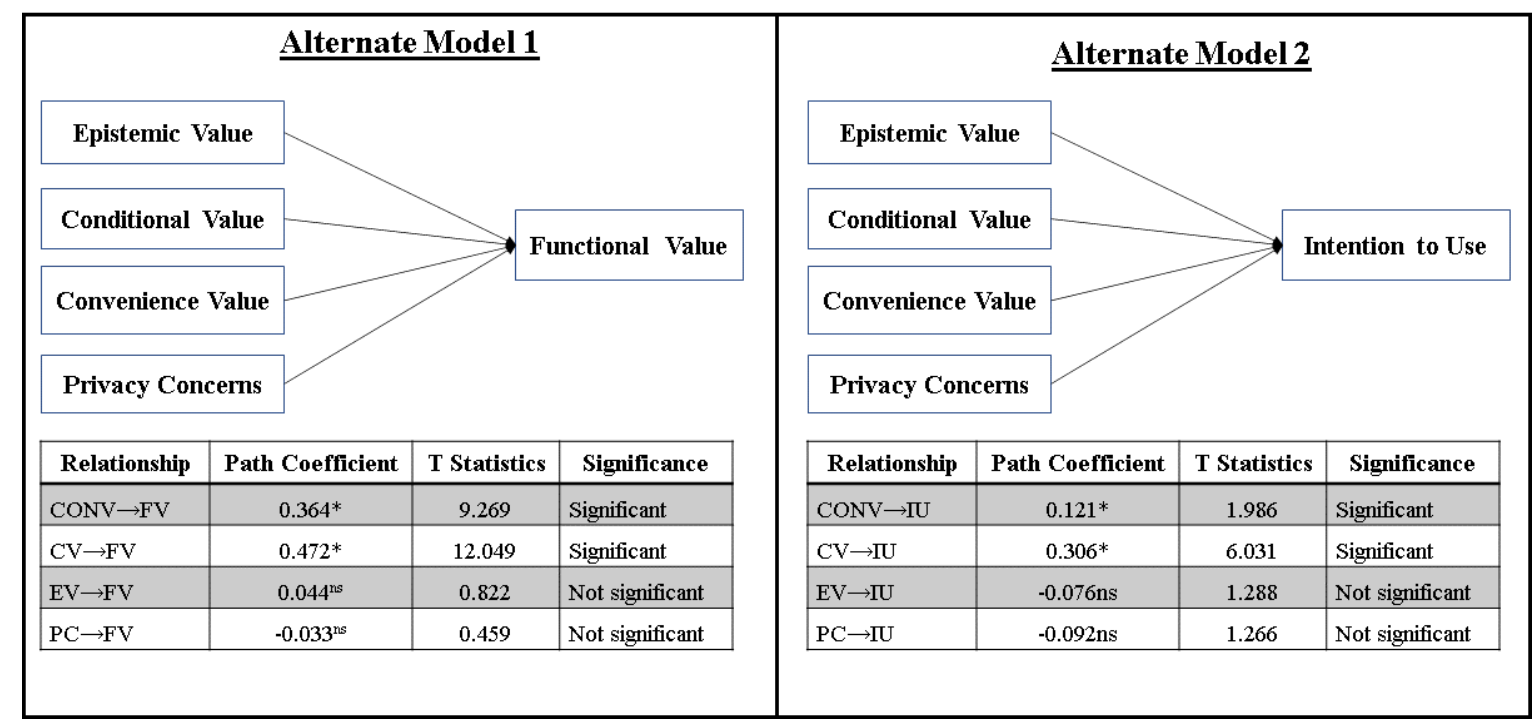

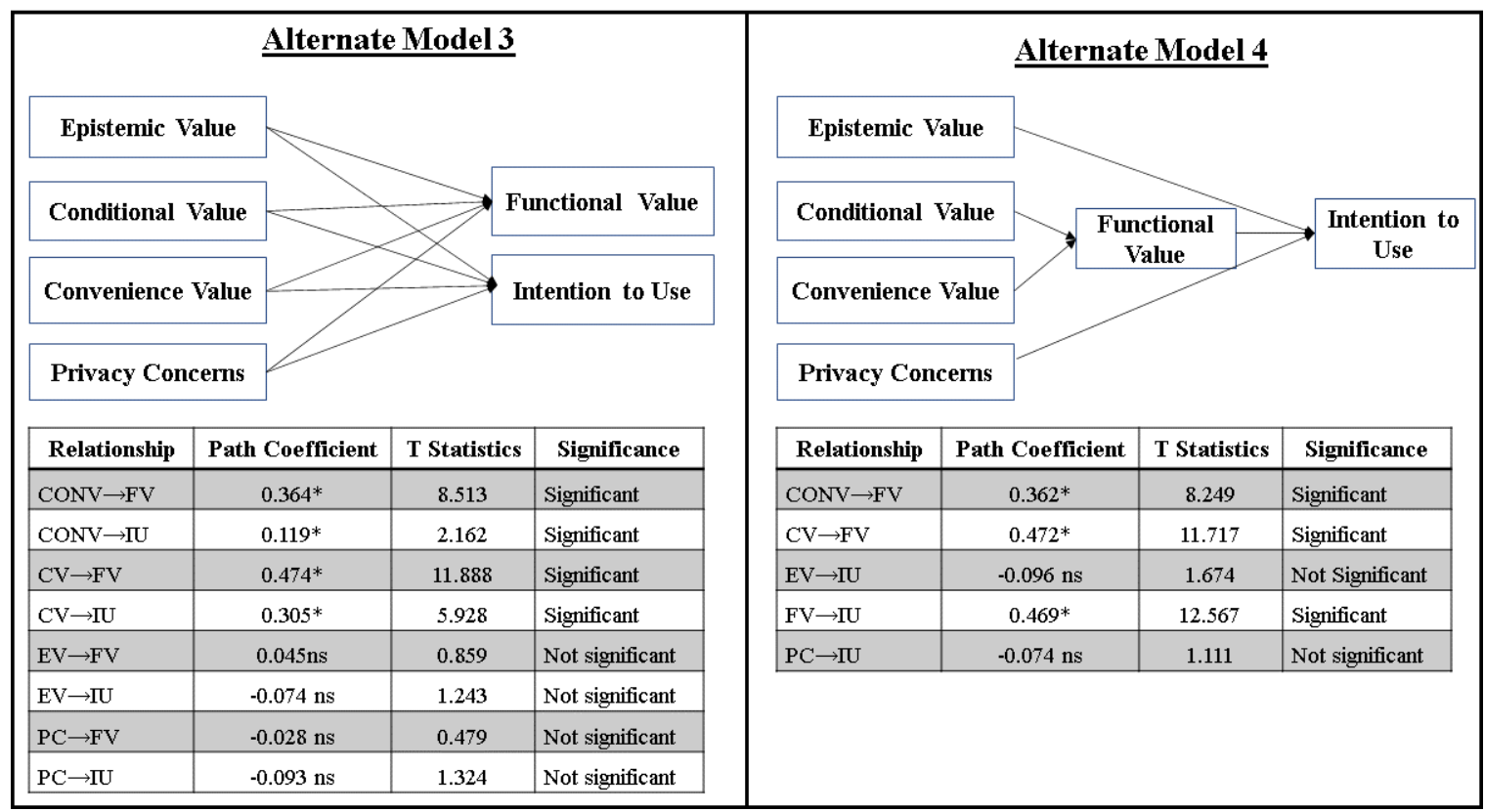

Figure 2. Alternate Models and Relationship Details 


\section{Conclusion}

This research study examines the determinants, especially related to consumption values and privacy concerns in the behavioral use intention among mobile phone users towards egovernance-initiated mobile app adoption during the COVID-19 pandemic. Among the determinants, it has been found that convenience value, conditional value, and functional value constructs have a significant impact on intention to use the mobile app. However, privacy concerns and epistemic value do not have a significant impact on intention to use it. Additionally, epistemic value does not have a significant impact on the perceived functional value of the mobile app.

The research model offers insights from two perspectives. First, it showcases how the government in any country can leverage the internet and mobile app technology to exercise the e-governance initiative, connect with its population, and share relevant information in realtime. This argument is in sync with the proposition made by Hasan and Linger (2020). Hasan and Linger (2020) argued how the practices of government bureaucracies can be overcome by the open nature of electronic-democracy (e-democracy). According to Toots (2019, p547), egovernance or e-democracy involves "...socio-technical information systems [acting] as instruments for democratic dialogue between citizens and governments." Globally, government organizations can look at leveraging digital technologies to enhance community engagement during exceptional scenarios, which in turn will build trust and acceptance among the general public towards e-governance initiatives.

The use of the contact tracing mobile app emerged as a very popular e-governance tool for the GoI by enabling it to maintain real-time connectivity and communication with more than 100 million people spread across India within 30 days of its launch. A similar trend is expected across other nations globally.

Second, it elaborates on how technology can be leveraged to promote the self-behavior orientation among the public in real-time. This generalization could be limited to an audience cohort that is largely well educated and internet-savvy. However, the behavioral intention of another cohort that was educated lower than degree level and was not Internet-savvy might be needed to ascertain the generalizability of this research. Next, we discuss the critical implications for theory and practice, followed by limitations and future research directions.

\subsection{Theoretical Implications}

From the theoretical point of view, this is one of the first research studies that has looked into the intention to use technology-based offerings from the perspective of both theory of consumption values and privacy theory. The article combined the theoretical constructs of consumption values with privacy concerns to investigate the intention to use among the users of the government-backed contact-tracing mobile app during the pandemic scenario. The use of an integrated approach in studying the intention to use technology-based offerings is a value addition to the existing research, since the majority of the existing research articles in this area have reviewed separately the influence of consumption values and privacy concerns on intention-to-use behavior towards technology-based offerings (Gu et al., 2017; Kumar et al., 2020; Xu et al., 2012; Zainuddin et al., 2013).

Second, it determines the factors constituting the functional value of e-governance initiatives in challenging situations. Third, the study contributes significantly to understanding the role of mobile apps in e-governance initiatives by the government, especially when there is a sense 
of urgency, which requires time-critical updates and communication to the country's citizens. This argument is in sync with the proposition made by Hasan and Linger (2020), who highlighted the role of internet and mobile technologies in gaining community engagement and mass mobilization while driving e-governance initiatives during exception scenarios.

Fourth, the study highlights the significance of testing alternative models on the same data-set in a particular context. This addition is important, especially in exceptional or new scenarios like the COVID-19 context. This alternative model approach is important to look beyond the dominant mindset or perception towards the specific research model, and thereby enhances learning about the relationship between different constructs (Boon-Itt \& Wong, 2016; Falbo et al., 2009). As the COVID-19 pandemic research context is severe and new to the Indian audience, we decided to test the alternate models and find if any alternative relationships could be explored.

\subsection{Practical Implications}

The present study also has significant implications from the perspective of practitioners. First, the study signifies the role of technology in triggering systemic behavior-change orientation among individuals in a specific region, society, or country. Contact-tracing mobile apps were launched by governments globally to provide timely updates to the citizens of their country during the COVID-19 pandemic situation. In this way, the governments discharged their responsibility of connecting people on a common technology platform for real-time communication, information, and guidelines during the exceptional situation of the COVID19 pandemic. At the same time, by doing this, governments expected the citizens of their country to exhibit alert and self-responsive behavior during the pandemic scenario, thereby minimizing the adverse impact during this exceptional situation.

Second, the study suggests that governments need to focus more on enhancing the functional value driven by convenience and context-specific features, rather than novelty aspects, to drive the willing adoption and use of an e-governance initiative among the citizens during a crisis. This finding is in synchronization with the argument made by Lee and Han (2015) as well as Lee et al. (2017). These articles highlighted the significance of context-driven usefulness and convenience values in stimulating the intention to use mHealth apps or services.

Third, during the COVID-19 pandemic, the success of e-governance initiatives undertaken by the governments of various nations in the context of adoption and intention to use for community-driven contact-tracing mobile apps by millions of people globally points at the scope for wider implications in different areas, especially for the people at the lower levels of the socio-economic pyramid. There is increasing scope for the community-oriented egovernance model, which is characterized by citizen engagement and public participation in real-time (Lee-Geiller \& Lee, 2019). E-governance initiatives in the form of government-tocitizens solutions enable bridging the institutional voids and empower the underserved population by providing real-time access to information in different areas (Khanra \& Joseph, 2019; Soma, Termeer, \& Opdam, 2016).

For example, there is an opportunity to launch an e-governance community-driven mobile app in the context of agriculture, which is linked to providing real-time access to vital information for farmers on soil quality, seeds, weather forecast, seasonal crops, expected demand levels, best pricing options, etc. from agriculture experts and community members. Similarly, e-governance mobile apps have huge scope for enabling access to real-time 
information on skill development, employability options, etc. for the underserved segment across the country.

\subsection{Limitations and Future Research Directions}

The current COVID-19 pandemic scenario has emerged as a fairly new and unexpected situation for the world. In view of this context, there are multiple areas in which research can be further enhanced for alternative theories and learning.

Future research could be conducted in the following areas. First, the current research has been conducted only amongst subjects that had installed the contact tracing mobile app on their smartphones in India. However, lately, as the GoI has facilitated contact-tracing mobile app services for feature phone owners through an IVRS service, future research could examine the influence of constructs like epistemic value, conditional value, convenience, privacy, and functional value on the intention to use in the context of subjects who are accessing the contact tracing mobile app service through feature phones in India and other developing nations.

Second, in the current research, India has been assumed to be a homogeneous cluster of citizens. However, India is a vast country with high diversity in terms of cultural, educational, religious, and societal factors. Future research could examine the moderating effect of these external factors and check if the relationship between the constructs tends to change. Third, the sample set in the current research is focused on just the end-users. In future research, academicians could focus on incorporating other stakeholders, such as policymakers or technology evangelists and explore the phenomenon from a multi-stakeholder perspective.

Fourth, as various countries have launched such mobile app initiatives to keep their respective citizens updated with the latest scenario about the COVID-19, multi-country research could be attempted to understand what differences existed between countries. This could lead to a much wider generalization of the model, hence leading to wider acceptability.

Fifth, this study has focused just on the behavioral intentions of the end-user. In the future, researchers, especially from the technology domain, could further explore the technology architecture and privacy-related factors in a much-detailed manner.

Sixth, the sample set for this study was restricted to a cohort that had at least a university degree as an education background, as the researchers could not go for face-to-face survey questionnaire administration. The behavioral intention of another cohort who was less educated could be studied in the future to understand if there was a difference in their intention to adopt any contact-tracing mobile app. Finally, this research did not consider the social status of the respondents (e.g., income). In the future, researchers can study the uptake of such apps among people of varying social status.

\section{References}

Aarogya Setu Website (2021). Retrieved January 9, 2021, from https://aarogyasetu.gov.in/ Agarwal, S., \& Sharma, Y. S. (2020). Aarogya Setu coming on feature phones; to cover the entire country. Retrieved September 21, 2020, from

https://economictimes.indiatimes.com/tech/software/aarogya-setu-coming-on-featurephones-to-cover-the-entirecountry/articleshow/75493148.cms?utm_source=contentofinterest\&utm_medium=text \&utm_campaign=cppst 
Agrebi, S., \& Jallais, J. (2015). Explain the intention to use smartphones for mobile shopping. Journal of Retailing and Consumer Services, 22, 16-23.

Alhassan, A., Li, L., Reddy, K., \& Duppati, G. (2020). Consumer acceptance and continuance of mobile money. Australasian Journal of Information Systems, 24. https://doi.org/10.3127/ajis.v24i0.2579

Altman, I. (1976). Privacy: A conceptual analysis. Environment and Behavior, 8(1),7-28.

Anckar, B., \& D'incau, D. (2002). Value creation in mobile commerce: Findings from a consumer survey. Journal of Information Technology Theory and Application, 4(1), 43-64.

Anderson, J. C., \& Gerbing, D. W. (1991). Predicting the performance of measures in a confirmatory factor analysis with a pretest assessment of their substantive validities. Journal of Applied Psychology, 76(5), 732-740.

Anderson, R.E., \& Srinivasan, S.S. (2003). E-satisfaction and e-loyalty: A contingency framework. Psychology \& marketing, 20(2), 123-138.

Angst, C. M., \& Agarwal, R. (2009). Adoption of electronic health records in the presence of privacy concerns: The elaboration likelihood model and individual persuasion. MIS Quarterly, 33(2), 339-370.

Banerjea, A. (2020). India's Aarogya Setu becomes world's highest downloaded app in just 13 days. Retrieved September 21, 2020, from https://www.livemint.com/technology/technews/india-s-aarogya-setu-becomes-world-s-highest-downloaded-app-in-just-13-days11586954392024.html

Boon-Itt, S., \& Wong, C. Y. (2016). Empirical investigation of alternate cumulative capability models: a multi-method approach. Production Planning \& Control, 27(4), 299-311.

Cengiz, E., \& Kirkbir, F. (2007). Customer perceived value: the development of a multiple item scale in hospitals. Problems and perspectives in management, 5(3), 252-268.

Chauhan, S., \& Kaushik, A. (2016). Evaluating citizen acceptance of unique identification number in India: an empirical study. Electronic Government, an International Journal, 12(3), 223-242.

Chen, G., \& Kotz, D. (2000). A survey of context-aware mobile computing research. Dartmouth Computer Science Technical Report TR2000-381. Retrieved September 21, 2020, from https://digitalcommons.dartmouth.edu/cgi/viewcontent.cgi?article=4201\&context=faco a

Chib, A., van Velthoven, M. H., \& Car, J. (2015). mHealth adoption in low-resource environments: a review of the use of mobile healthcare in developing countries. Journal of Health Communication, 20(1), 4-34.

Chin, W.W., \& Newsted, P.R. (1999). Structural equation modeling analysis with small samples using partial least squares. Statistical Strategies for Small Sample Research, 1(1), 307-341.

Chow, W. S., \& Shi, S. (2014). Investigating students' satisfaction and continuance intention toward e-learning: An Extension of the expectation-confirmation model. Procedia-Social and Behavioral Sciences, 141, 1145-1149. 
Churchill Jr, G. A. (1979). A paradigm for developing better measures of marketing constructs. Journal of Marketing Research, 16(1), 64-73.

Clarance, A. (2020). Aarogya Setu: Why India's Covid-19 contact tracing app is controversial. Retrieved September 21, 2020, from https://www.bbc.com/news/world-asia-india52659520

Colwell, S. R., Aung, M., Kanetkar, V., \& Holden, A. L. (2008). Toward a measure of service convenience: multiple-item scale development and empirical test. Journal of Services Marketing, 22(2), 160-169.

Davis, F. D., Bagozzi, R. P., \& Warshaw, P. R. (1989). User acceptance of computer technology: a comparison of two theoretical models. Management Science, 35(8), 982-1003.

Dhaggara, D., Goswami, M., \& Kumar, G. (2020). Impact of Trust and Privacy Concerns on Technology Acceptance in Healthcare: An Indian Perspective. International Journal of Medical Informatics, 141, 104164.

Dinev, T., \& Hart, P. (2006). An extended privacy calculus model for e-commerce transactions. Information Systems Research, 17(1), 61-80.

Falbo, T., Kim, S., \& Chen, K. Y. (2009). Alternate models of sibling status effects on health in later life. Developmental Psychology, 45(3), 677-687.

Farronato, C., Iansiti, M., Bartosiak, M., Denicolai, S., Ferretti, L., \& Fontana, R. (2020). How to Get People to Actually Use Contact-Tracing Apps. Harvard Business Review Digital Articles. Retrieved September 18, 2020, from https://hbr.org/2020/07/how-to-get-peopleto-actually-use-contact-tracing-apps

Fishbein, M., \& Ajzen, I. (1975). Belief, attitudes, intention, and behavior: An introduction to theory and research. Reading, MA: Addison-Wesley.

Firstpost (2020). Aarogya Setu: Lack of Data Privacy Laws, Transparent Policies Make App Worrisome, Say MIT Researchers. Retrieved September 21, 2020, from https://www.firstpost.com/tech/news-analysis/aarogya-setu-the-mandatory-contacttracing-app-of-india-gets-reviewed-by-mit-university-here-is-what-they-think8354661.html

Fornell, C., \& Larcker, D. F. (1981). Evaluating structural equation models with unobservable variables and measurement error. Journal of Marketing Research, 18(1), 39-50.

Garg, S., Bhatnagar, N., \& Gangadharan, N. (2020). A case for participatory disease surveillance of the COVID-19 pandemic in India. JMIR Public Health and Surveillance, 6(2), e18795.

Ghosh, A., Nundy, S., \& Mallick, T. K. (2020). How India is dealing with COVID-19 pandemic. Sensors International, 1, 100021.

Gonçalves, H. M., Lourenço, T. F., \& Silva, G. M. (2016). Green buying behavior and the theory of consumption values: A fuzzy-set approach. Journal of Business Research, 69(4), 14841491.

Gu, J., Xu, Y. C., Xu, H., Zhang, C., \& Ling, H. (2017). Privacy concerns for mobile app download: An elaboration likelihood model perspective. Decision Support Systems, 94, 19-28. 
Hair, J. F., Black, W. C., Babin, B. J., Anderson, R. E., \& Tatham, R. L. (2010). Multivariate data analysis ( $7^{\text {th }}$ ed.). NJ: Pearson Prentice Hall, Uppersaddle River.

Hasan, H., \& Linger, H. (2020). Letting the public in: Dialectic tensions when governments use ICT to engage citizens. Australasian Journal of Information Systems, 24. https://doi.org/10.3127/ajis.v24i0.1897

Hew, T. S., \& Kadir, S. L. S. A. (2017). Applying Channel Expansion and Self-Determination Theory in predicting use behaviour of cloud-based VLE. Behaviour $\mathcal{E}$ Information Technology, 36(9), 875-896.

Hill, T., Smith, N. D., \& Mann, M. F. (1987). Role of efficacy expectations in predicting the decision to use advanced technologies: The case of computers. Journal of Applied Psychology, 72(2), 307-313.

Hoehle, H., \& Venkatesh, V. (2015). Mobile application usability: conceptualization and instrument development. MIS Quarterly, 39(2), 435-472.

Holbrook, M. B. (1994). The nature of customer value: an axiology of services in the consumption experience. Service quality: New directions in theory and practice, 21(1), 21-71.

Immuni Website (2021). Retrieved February 7, 2021, from https://www.immuni.italia.it/ dashboard.html

Iqbal, N., \& Dar, K. A. (2020). Coronavirus disease (COVID-19) pandemic: Furnishing experiences from India. Psychological Trauma: Theory, Research, Practice, and Policy, 12(S1), S33-S34.

Khanra, S., \& Joseph, R. P. (2019). Adoption of e-Governance: the mediating role of language proficiency and digital divide in an emerging market context. Transforming Government: People, Process and Policy, 13(2), 122-142.

Kijsanayotin, B., Pannarunothai, S., \& Speedie, S. M. (2009). Factors influencing health information technology adoption in Thailand's community health centers: Applying the UTAUT model. International Journal of Medical Informatics, 78(6), 404-416.

Kilbourne, W., \& Pickett, G. (2008). How materialism affects environmental beliefs, concern, and environmentally responsible behavior. Journal of Business Research, 61(9), 885-893.

Kumar, R., Sachan, A., \& Kumar, R. (2020). The impact of service delivery system process and moderating effect of perceived value in internet banking adoption. Australasian Journal of Information Systems, 24. https://doi.org/10.3127/ajis.v24i0.1923

Lah, F. (2008). Are IP addresses "personal identifiable information"? I/S: A Journal of Law and Policy for the Information Society, 4(3), 681-706.

Lee, E., \& Han, S. (2015). Determinants of adoption of mobile health services. Online Information Review, 39(4), 556-573.

Lee, E., Han, S., \& Jo, S. H. (2017). Consumer choice of on-demand mHealth app services: Context and contents values using structural equation modeling. International Journal of Medical Informatics, 97, 229-238.

Lee, M. C. (2010). Explaining and predicting users' continuance intention toward e-learning: An extension of the expectation-confirmation model. Computers $\mathcal{E}$ Education, 54(2).506516. 
Lee-Geiller, S., \& Lee, T. D. (2019). Using government websites to enhance democratic Egovernance: A conceptual model for evaluation. Government Information Quarterly, 36(2), 208-225.

Leitner, C. (2003). eGovernment in Europe: The State of Affairs. European Institute of Public Administration, Maastricht.

Lim, W. M. (2018a). Dialectic antidotes to critics of the technology acceptance model: Conceptual, methodological, and replication treatments for behavioural modelling in technology-mediated environments. Australasian Journal of Information Systems, 22. https://doi.org/10.3127/ajis.v22i0.1651

Lim, W. M. (2018b). Revisiting concepts and theories in information systems and technology. Australasian Journal of Information Systems, 22. https://doi.org/10.3127/ajis.v22i0.1733

Lim, W. M., Lim, A. L., \& Phang, C. S. C. (2019). Toward a conceptual framework for social media adoption by non-urban communities for non-profit activities: Insights from an integration of grand theories of technology acceptance. Australasian Journal of Information Systems, 23. https://doi.org/10.3127/ajis.v23i0.1835

Livemint (2020). More than $50 \%$ of India's population 25 yrs or older: Survey. Retrieved September 15, 2020, from https://www.livemint.com/news/india/more-than-50-of-indias-population-25-yrs-or-older-survey-11593793054491.html

Lohchab, H. (2019). Overall, India handset market growth to fall in 2020. Retrieved September 21, 2020, from https://economictimes.indiatimes.com/tech/hardware/overall-indiahandset-market-growth-to-fall-in-2020/articleshow/72950192.cms?from=mdr

Long, M.M., \& Schiffman, L.G. (2000). Consumption values and relationships: Segmenting the market for frequency programs. Journal of Consumer Marketing, 17(3), 214-232.

Lu, H. K., Lin, P. C., \& Chen, A. N. (2017). An empirical study of behavioral intention model: Using learning and teaching styles as individual differences. Journal of Discrete Mathematical Sciences and Cryptography, 20(1), 19-41.

Lu, J., Yao, J. E., \& Yu, C. S. (2005). Personal innovativeness, social influences and adoption of wireless Internet services via mobile technology. The Journal of Strategic Information Systems, 14(3), 245-268.

MacKenzie, S. B., Podsakoff, P. M., \& Podsakoff, N. P. (2011). Construct measurement and validation procedures in MIS and behavioral research: Integrating new and existing techniques. MIS Quarterly, 35(2), 293-334.

O'Neill, P.H., Ryan-Mosley, T., \& Johnson, R. (2020). A flood of coronavirus apps are tracking us. Now it's time to keep track of them. Retrieved September 21, 2020, from https://www.technologyreview.com/2020/05/07/1000961/launching-mittr-covid-tracingtracker/

O'Neill, P. H. (2020). India is forcing people to use its covid app, unlike any other democracy. Retrieved September 18, 2020, from https://www.technologyreview.com/2020/05/07/ 1001360/india-aarogya-setu-covid-app-mandatory/

Okazaki, S. (2008). Exploring experiential value in online mobile gaming adoption. Cyberpsychology \& Behavior, 11(5), 619-622. 
Pagani, M. (2004). Determinants of adoption of third generation mobile multimedia services. Journal of Interactive Marketing, 18(3), 46-59.

Pan, S. L., \& Zhang, S. (2020). From fighting COVID-19 pandemic to tackling sustainable development goals: An opportunity for responsible information systems research. International Journal of Information Management, 55, 102196.

Pihlström, M., \& Brush, G. J. (2008). Comparing the perceived value of information and entertainment mobile services. Psychology \& Marketing, 25(8), 732-755.

Podsakoff, P. M., MacKenzie, S. B., Lee, J. Y., \& Podsakoff, N. P. (2003). Common method biases in behavioral research: a critical review of the literature and recommended remedies. Journal of Applied Psychology, 88(5), 879-903.

Pura, M. (2005). Linking perceived value and loyalty in location-based mobile services. Managing Service Quality, 15(6), 509-538.

Reuters (2020). Italy launches COVID-19 contact-tracing app amid privacy concerns. Retrieved February 7, 2021, from https://www.reuters.com/article/us-health-coronavirus-italyapp-idINKBN2383EW

Rintamäki, T., Kanto, A., Kuusela, H., \& Spence, M. T. (2006). Decomposing the value of department store shopping into utilitarian, hedonic and social dimensions. International Journal of Retail \& Distribution Management, 34(1), 6-24.

Rokeach, M. (1968). A Theory of Organization and Change Within Value-Attitude Systems. Journal of Social Issues, 24(1), 13-33.

Sarkar, S., Chauhan, S., \& Khare, A. (2020). A meta-analysis of antecedents and consequences of trust in mobile commerce. International Journal of Information Management, 50, 286-301.

Saxena, K. B. C. (2005). Towards excellence in e-governance. International Journal of Public Sector Management, 18(6), 498-513.

Sheth, J. N., Newman, B. I., \& Gross, B. L. (1991). Why we buy what we buy: A theory of consumption values. Journal of Business Research, 22(2), 159-170.

Shroff, R. H., \& Keyes, C. J. (2017). A proposed framework to understand the intrinsic motivation factors on university students' behavioral intention to use a mobile application for learning. Journal of Information Technology Education: Research, 16(1), 143168.

Singh, M., \& Sahu, G. P. (2018). Study of e-governance implementation: a literature review using classification approach. International Journal of Electronic Governance, 10(3), 237-260.

Singh, S. (2020). An integrated model combining ECM and UTAUT to explain users' postadoption behavior towards mobile payment systems. Australasian Journal of Information Systems, 24. https://doi.org/10.3127/ajis.v24i0.2695

Smith, H. J., Dinev, T., \& Xu, H. (2011). Information privacy research: An interdisciplinary review. MIS Quarterly, 35(4), 989-1016.

Soma, K., Termeer, C. J., \& Opdam, P. (2016). Informational governance-A systematic literature review of governance for sustainability in the Information Age. Environmental Science \& Policy, 56, 89-99. 
Statistics Times (2020). Population of India. Retrieved September 15, 2020, from http://statisticstimes.com/demographics/country/india-population.php

Steenkamp, J. B. E., \& Baumgartner, H. (1992). The role of optimum stimulation level in exploratory consumer behavior. Journal of Consumer Research, 19(3), 434-448.

Stemberger, M. I., \& Jaklic, J. (2007). Towards E-government by business process change-A methodology for public sector. International Journal of Information Management, 27(4), 221232.

The Economic Times (2020). Rahul Gandhi raises security, privacy concerns over Aarogya Setu app. Retrieved September 21, 2020, from https://economictimes.indiatimes.com/news/politics-and-nation/rahul-gandhi-raisessecurity-privacy-concerns-over-arogya-setu-app/articleshow/75508771.cms

The Hindu (2020). Data I How safe is Aarogya Setu compared to COVID-19 contact tracing apps of other countries? Retrieved September 21, 2020, from https://www.thehindu.com/data/how-safe-is-aarogya-setu-compared-to-contacttracing-apps-of-other-countries/article31618852.ece

The Quint (2020). MIT Researchers Downgrade Aarogya Setu App to One Star in Review. Retrieved September 21, 2020, from https://www.thequint.com/tech-and-auto/technews/aarogya-setu-app-gets-one-star-out-of-five-in-mit-review

The Times of India (2020). Government launches Covid-19 tracking app Aarogya Setu. Retrieved September 21, 2020, from http://timesofindia.indiatimes.com/articleshow/ 74946627.cms?utm_source=contentofinterest\&utm_medium=text\&utm_campaign= cppst

Toots, M. (2019). Why E-participation systems fail: The case of Estonia's Osale.ee. Government Information Quarterly, 36(3), 546-559.

Tzeng, J. Y. (2011). Perceived values and prospective users' acceptance of prospective technology: The case of a career eportfolio system. Computers $\mathcal{E}$ Education, 56(1), 157-165.

Vinson, D. E., Scott, J. E., \& Lamont, L. M. (1977). The role of personal values in marketing and consumer behavior. Journal of Marketing, 41(2), 44-50.

Wang, H. Y., Liao, C., \& Yang, L. H. (2013). What affects mobile application use? The roles of consumption values. International Journal of Marketing Studies, 5(2), 11-22.

Westin, A. F. (2003). Social and political dimensions of privacy. Journal of Social Issues, 59(2), 431-453.

Worldometer (2021). Countries in the world by population (2021). Retrieved February 20, 2021, from https://www.worldometers.info/world-population/population-by-country/

Xu, H., Teo, H. H., Tan, B. C., \& Agarwal, R. (2012). Research note-effects of individual selfprotection, industry self-regulation, and government regulation on privacy concerns: a study of location-based services. Information Systems Research, 23(4), 1342-1363.

Yang, H.-L., \& Lin, R.-X. (2017). Determinants of the intention to continue use of SoLoMo services: Consumption values and the moderating effects of overloads. Computers in Human Behavior, 73, 583-595. 
Zainuddin, N., Russell-Bennett, R. \& Previte, J. (2013). The value of health and wellbeing: an empirical model of value creation in social marketing. European Journal of Marketing, 47(9), 1504-1524.

Zandifar, A., \& Badrfam, R. (2020). Iranian mental health during the COVID-19 epidemic. Asian Journal of Psychiatry, 51, 101990.

Zhang, Y., Yu, P., \& Shen, J. (2012). The benefits of introducing electronic health records in residential aged care facilities: a multiple case study. International Journal of Medical Informatics, 81(10), 690-704.

Copyright: (C) 2021 authors. This is an open-access article distributed under the terms of the Creative Commons Attribution-NonCommercial 3.0 Australia License, which permits noncommercial use, distribution, and reproduction in any medium, provided the original author and AJIS are credited.

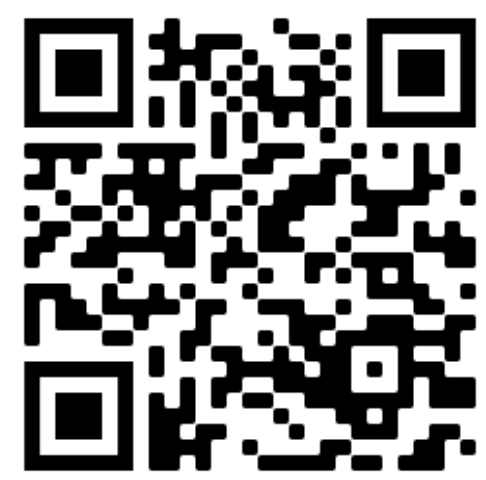

